\title{
Electronic journals have a future
}

A conference on changing patterns of journal publication suggests that electronic journals may already have arrived, but that their management remains a problem for the future.

\section{Chicago}

EVERYBODY agrees that the world's journals are in flux, but nobody is sure what the future holds - or even when it will arrive. That was the general drift of a conference on "The role of journals in scholarly communication", held last week as part of the centenary celebration of the University of Chicago, still recognizably distinctive for its interdisciplinarity, for the intellectual daring of its faculty and for the unobtrusiveness of its administration.

What follows is not so much a formal report of the proceedings (which would be professionally improper for a participant) as an account of some of the issues raised by people who edit journals, who are responsible for buying them (librarians), who are sociologists of science or who are otherwise students of the phenomenon of the recent growth of the literature of scholarship. But that phenomenon defies accurate census.

For one thing, it is easier to count new titles than to record those that disappear. More important, the division between scholarship and journalism is not always sharp; Addison's Spectator rated several mentions, as did the New York Review of Books and the Times Literary Supplement. But nobody carried a torch for Scientific American or La Recherche, leaving unanswered the question of the role of good popularization in communication among scientists. But Ann Okerson from the Association of Research Libraries in Washington, DC, noted that 29,000 new serial titles appeared between 1978 and 1987, and estimated that the total extant is close to 250,000 . (She also estimates that a year's supply of the journals indexed by the Medline database would be twice as high as the Washington Monument.

What drives this huge and expensive growth? Even accepting that scholarship has grown enormously, and the common railings last week at duplicate publication and the serial publication of breathless interim reports on progress ('salami slices'), the phenomenon calls for an explanation. The common thread in most explanations is that scholarly publishing has become a kind of vanity press, existing to serve the interests of its contributors. And why is that interest so clamant? That unpublished scholarship might as well never have been done is a principle generally accepted, but the use of published works, perhaps even weighted by a citation index, has also become a standard influence in academic appointments and promotions.

Budget-conscious librarians last week complained not merely at publishers (who have increased the average prices of journals three times more quickly, in the past few years, than ordinary retail prices), but at their academic colleagues, who are given to insisting on subscriptions to journals in which they have published, however untried and expensive. The irony is that their problems (and those of journals) would be simplified if only the link between publication and promotion could be broken or made less tyrannical. But scholarship seems not yet ready to contemplate solutions.

That is one reason why electronic communications were given a generous green light last week. (Another is that electronic journals offer facilities denied the users of ink-on-paper journals, the facility to call up from within a text being read the text of another referred to, for example). Other conventional journals are seeking to meet librarians' anxieties about storage costs by exploit ing the compactness of the compact disk, and would be helped by accepted standards. But the notion that full-blown electronic journals will soon be multiplying was taken for granted, although the question of just when that will be is still open.

Dr Edward Huth, for 19 years a distinguished editor of the Journal of Internal Medicine, is about to find out. He is the first editor of the electronic journal the American Association for the Advancement of Science plans to launch in July. The journal will carry reports of clinical trials with new drugs and treatments. Huth's enthusiasm for the project only partly derives from his ambition to get rid of the bias in conventional journals against reports showing clinical innovations to be ineffective. It will also be a proving ground for a new technology, a source of information about the economics of the operation and a way of assessing what the end-users really want.

That will be a formal journal, with every article put out rigorously refereed. By Okerson's account, informal electronic publishing is already streets ahead. The innovators are the physicists, whose use of academic computer networks for the distribution of preprints is a fact of life. She quoted without evident disapproval one physicist's declaration that the "technological issues are already settled, . . the demise of certain journals has been under way for more than a decade, ... we have learned to determine by title and abstract whether we wish to read a paper, .. the small amount of filtering provided by refereed journals plays no effective role in our research".
There was not much dissent from Okerson's opinion that this trend will continue. Indeed, she notes that usage of the US network Internet is growing at 15 per cent a month, that an estimated 5 million people worldwide have access to some interconnected network (of which there are an estimated 7,500) and that a system in which anonymous reviewers' comments are replaced by the comments of identifiable critics and held with the same records might even be an improvement of the literature. And, the argument continues, much paper would be saved.

Even before that usage is general, the concept of the journal as an integrated whole may have withered away. Okerson quoted a chilling figure: of the 1.5 million items supplied to each other by her member-libraries last year, an estimated twothirds consisted of single copies of articles from journals. In short, there is already a brisk trade in the components of journals rather than in the journals themselves. When the electronic age dawns, people will routinely be searching the networks for single research articles, raising awkward questions about the ownership of copyright.

There are other awkward questions, not fully discussed last week. One is the degree to which electronic publication within the research networks will satisfy individuals' wishes that the importance of their work should be recognized not merely by their fellow network users, but by their masters. If the research community is not ready to cut the link between promotion and publication, perhaps the sociologists of science should find out.

There is an even darker question, arising from the circumstance that the electronic networks as they are cost academic users (and even, sometimes, their institutions) nothing. What will happen if the governments at present meeting the costs of networks start making realistic charges for their use? Or if they make discriminatory charges against, say, foreign access? Or even have views about the nature of the material made available? Such developments, unlikely though they may be, could seriously damage the health of the research community.

Nature is for the time being an observer, not a participant, in these affairs. Issues of access from out-of-the-way places argue for it to remain an ink-on-paper journal. But even journals such as this might usefully have electronic antecedents at some stage. Last week's enthusiasm argues for sooner, not later.

John Maddox 